\title{
The perception of Obstructive Sleep Apnoea/ Hypopnoea Syndrome (OSAHS) among Italian general practitioners
}

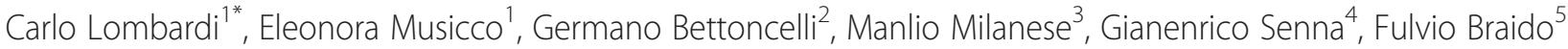 \\ and Giorgio Walter Canonica ${ }^{5}$
}

\begin{abstract}
Background: Obstructive Sleep Apnoea/Hypopnoea Syndrome (OSAHS) is a common disorder in the general population but often underestimated and underdiagnosed.

Methods: This questionnaire-based study evaluated the overall level of knowledge about OSAHS among Italian General Practitioners (GPs), who are frequently involved in the management of this complex disease. This represents an interesting aspect, because GPs intercept many of the patients with OSAHS, in which C-PAP could be potentially indicated. Randomly-selected GPs were provided with questionnaires, which were then returned anonymously.

Results: 80 questionnaires have been validated; the participants in the sample examined were represented by 43 females and 37 males; the average age of participants was 51 years. The general knowledge on OSAHS is overall satisfactory among GPs; it is recognized by most of the GPs interviewed as pathology in constant increase, and associated with predisposing factors such as obesity. High blood pressure is perceived as an independent cardiovascular risk factor in patients with OSAHS, in line with the majority of international studies. The C-PAP has been identified as the care gold standard in patients with OSAHS, despite the lack of patient compliance in relation to this procedure, while polysomnography was found to be the main instrumental procedure used in the diagnostic workup of OSAS. The pulmonologist and a multidisciplinary team have been identified as the specialist figures of reference to which to direct the patient through the diagnostic workup. Respiratory therapists and nurses represent the role of educator in the proper management of the C-PAP in the opinion of $62 \%$ of respondents, while only $34 \%$ think that this role should be played by the GPs and/or other specialists.
\end{abstract}

Conclusions: In conclusion, this survey about the perception of OSAHS among GPs in Italy highlighted a satisfactory overall knowledge of OSAHS and only few weak points.

Keywords: Obstructive Sleep Apnoea/ Hypopnoea Syndrome (OSAHS), General Practitioners (GPs), Polysomnography, Mechanical ventilation with positive airway pressure (C-PAP)

\section{Background}

OSAHS is a common disorder in the general population but often underestimated and underdiagnosed [1]. The definition of the Obstructive Sleep Apnoea/Hypopnoea Syndrome (OSAHS) cannot be separated from an integration of clinical and instrumental data. Clinically, OSAHS is characterized by excessive daytime sleepiness and/or

\footnotetext{
* Correspondence: carlo.lombardi@poliambulanza.it

${ }^{1}$ Allergy and Pneumology Departmental Unit, Fondazione Poliambulanza Hospital, Brescia, Italy

Full list of author information is available at the end of the article
}

alterations to the performance day and night snoring; from the pathophysiological point of view OSAHS is characterized by the occurrence during sleep of repeated episodes of partial or complete obstruction of the upper airways that are associated with oxygen concentration phasic reductions resulting in oxygen desaturation of arterial hemoglobin [2]. There are different degrees of obstruction of the upper airways that can determine the different respiratory events: complete obstruction (obstructive sleep apnea) and partial obstructions (divided into: hypopneas and Respiratory Effort Related Arousal 
Table 1 "Questionnaire distributed to the participating Italian general practitioners (GPs)"

\begin{tabular}{|c|c|}
\hline \multirow[t]{5}{*}{ 1. What is the definition commonly used for OSAHS? } & A) Daytime sleepiness associated with irregular breathing at night \\
\hline & $\begin{array}{l}\text { B) Episodes of paroxysmal dyspnea caused by obstruction of the } \\
\text { upper and lower respiratory tract }\end{array}$ \\
\hline & C) Obstructive Sleep apnea induced by gastroesophageal reflux \\
\hline & $\begin{array}{l}\text { D) Obstructive Sleep Apnea induced by persistent rhinitis } \\
\text { characterized by nasal obstruction }\end{array}$ \\
\hline & E) Obstructive Sleep Apnea induced by nocturnal asthmatic attack \\
\hline \multirow[t]{4}{*}{ 2. In the western countries, which is the males prevalence of OSAHS? } & A) $2 \%$ \\
\hline & B) $4 \%$ \\
\hline & C) $8 \%$ \\
\hline & D) $10 \%$ \\
\hline \multirow[t]{4}{*}{ 3. In the western countries, which is the females prevalence of OSAHS? } & A) $2 \%$ \\
\hline & B) $4 \%$ \\
\hline & C) $8 \%$ \\
\hline & D) $10 \%$ \\
\hline \multirow[t]{4}{*}{ 4. Among your patients, how many have a diagnosis of OSAHS? } & A) No one \\
\hline & B) $0-5$ \\
\hline & C) $5-10$ \\
\hline & D) $>10$ \\
\hline \multirow[t]{4}{*}{ 5. The number of OSAHS patients in recent years has been: } & A) Stationary \\
\hline & B) In growth \\
\hline & C) In reduction \\
\hline & D) Do not know \\
\hline \multirow[t]{5}{*}{ 6. OSAHS episodes of apnea/hypopnea can be of type: } & A) Obstructive \\
\hline & B) Central \\
\hline & C) Mixed \\
\hline & D) All of the above \\
\hline & E) Restrictive \\
\hline
\end{tabular}

7. Is it true that obese people present a higher risk of developing OSAHS?

A) Yes

B) No

C) Yes, but only women and children

D) Yes, but also normal weight individuals can be affected

8. What is the prevalence of OSAHS in the hypertensive patients?

A) $<5 \%$

B) Between 10 and 20\%

C) Between 20-40\%

D) $>50 \%$

9. Do you think that OSAHS should be considered an independent

A) Yes cardiovascular risk factor?

\section{B) No}

C) I don't know

10. Are you aware of the questionnaire referred to as "Epworth Sleepiness Scale"?

\section{A) Yes, I use it in my professional activity}

B) Yes, but do not use it

C) No, I do not know 
Table 1 "Questionnaire distributed to the participating Italian general practitioners (GPs)" (Continued)

\begin{tabular}{|c|c|}
\hline \multirow{7}{*}{$\begin{array}{l}\text { 11. In the suspected diagnosis of OSAHS, what is the specialist that you } \\
\text { turn more often in the first place? }\end{array}$} & A) ENT Specialist \\
\hline & B) Pulmonologist \\
\hline & C) Allergist \\
\hline & D) Internist \\
\hline & E) Multidisciplinary Team \\
\hline & F) Speech Therapist \\
\hline & G) Psychologist/Psychiatrist \\
\hline \multirow{4}{*}{$\begin{array}{l}\text { 12. When accessing the specialist's assessment, which are the main } \\
\text { problems you encounter? }\end{array}$} & A) Waiting time \\
\hline & B) Costs \\
\hline & C) Communication with the specialist \\
\hline & D) Degree of belief of the patient \\
\hline \multirow{6}{*}{$\begin{array}{l}\text { 13. Which exam do you see as the most crucial for an accurate diagnosis } \\
\text { of OSAHS? }\end{array}$} & A) Spirometry \\
\hline & B) Maxilo-facial CT \\
\hline & C) Determination of nocturnal oximetry in continuous \\
\hline & D) Polysomnography \\
\hline & E) EEG \\
\hline & F) ECG Holter with integrated pressure arterial Holter \\
\hline \multirow[t]{10}{*}{ 14. What is the OSAHS treatment of choice? } & A) Nasal septum plastic intervention \\
\hline & B) Uvulopalatopharyngoplasty (UPPP) \\
\hline & C) Treatment with topical nasal steroids \\
\hline & $\begin{array}{l}\text { D) Topical association therapy with bronchial Long Acting } \\
\text { Bronchodilators (LABAs) and steroids (iCSs) }\end{array}$ \\
\hline & E) Nocturnal Oxygen continuous \\
\hline & F) C-PAP \\
\hline & G) Intraoral Orthodontic Devices \\
\hline & H) Sleeping pharmacological agent (like benzodiazepines) \\
\hline & I) Psychological approach \\
\hline & L) Yoga \\
\hline \multirow{3}{*}{$\begin{array}{l}\text { 15. When C-PAP is prescribed, patient reaction to the treatment is } \\
\text { predominantly of : }\end{array}$} & A) Total refusal \\
\hline & B) Total adherence \\
\hline & C) Lack of acceptance \\
\hline \multirow{4}{*}{$\begin{array}{l}\text { 16. Who primarily has the responsibility of educating and supporting the } \\
\text { patient in correcting and adjusting the C-PAP?" }\end{array}$} & A) GP \\
\hline & B) Specialist \\
\hline & C) Nurse \\
\hline & D) Respiratory Physiotherapist \\
\hline
\end{tabular}

(RERA). According to international standards for the diagnosis of OSAHS, the duration of respiratory events of each of the types described above shall not be less than 10 seconds and no more than 3 minutes. The relief of the obstructive events are processed using polygraphic instruments recording the activity of the subject during an entire night's sleep [3]. The registration of an average number of complete obstructive respiratory events (apneas) and/or incomplete (hypopneas, RERA) per hour of sleep (RDI, Respiratory Disorder Index), equal to or $>10$, configure a condition of OSAHS in adult subject. Several lines of evidence have identified OSAHS as an independent risk factor of secondary hypertension, such as obesity [4-6]. The treatment of OSAHS includes procedures such as mechanical ventilation with positive airway pressure (C-PAP), orthodontic devices, weight loss in obese subjects, positional 


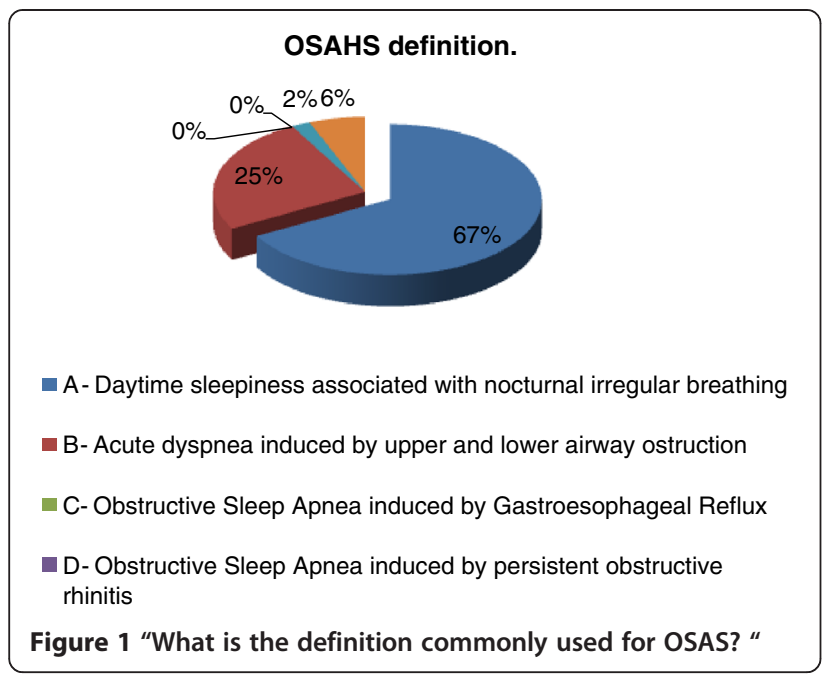

therapy and surgery in those patients who have episodes of obstructive apnea sleeping supine. Some studies have shown that C-PAP improves daytime and nighttime blood pressure in patients with moderate and severe OSAHS, highlighting the importance of management and adherence to C-PAP therapy, in particular to normalize the oxygen concentration [7]. The present study evaluated the overall level of knowledge about OSAHS among italian General Practitioners (GPs), who are frequently involved in the management of this complex disease. This represents an interesting aspect, because GPs intercept many of the patients with chronic illness [8], as OSAHS, in which C-PAP could be potentially indicated.

\section{Methods}

The results of this study were obtained through the completion of an anonymous questionnaire, created "ad hoc" and based on the guidelines and the current literature, by a panel of experts composed by General Practitioners (GPs) and Specialists (like Pneumologists, ENT specialists, and Allergologists). It consists of 16 items (Table 1) and is distributed to GPs to assess the level of knowledge of the clinical and therapeutical problems linked to OSAHS.
Questionnaires were e-mailed to GPs over the entire territory of Brescia, a northern town of Italy, and had to be returned anonymously. Only the fully completed questionnaires were considered for the descriptive statistics. 80 questionnaires have been validated. The participants in the sample examined were represented by 43 females and 37 males; the age range of participants was : 34-65 years, and the average age was 51 years. Written informed consent was obtained for publication of this report.

\section{Results}

As a general result, a good knowledge of the definition of OSAHS emerged from the results, with $67 \%$ of correct answer to the corresponding question in the questionnaire (Figure 1). An adequate level of knowledge is also found for the epidemiological data (Figure 2). OSAHS has a prevalence of $4 \%$ in males and $2 \%$ in female subjects aged between 30 and 60 years, $1 \%$ of preschool children and $11 \%$ in those aged $>61$ years. More than half of the participants answered the question correctly on the prevalence of OSAHS in men (52\% correct answers) and female (59\% of correct answers). The prevalence of OSAHS among GPs surveyed is found to be low $(0-0.5 \%)$ in line with the known under-diagnosis of OSAHS in the general population. The incidence of OSAS in the general population is $11 \%$ and is in constant increase, as correctly perceived by GPs participating in the study ( $54 \%$ of correct answers). Instead, poor knowledge of the underlying pathophysiological mechanisms seems to emerge, with only $46 \%$ of respondents correctly answering to the question on apnea/ hypopnea in OSAHS). On the other side, most of the GPs perceive the importance of the association between OSAHS and obesity (71\%) and between OSAHS and hypertension (63\% of respondents), although in the latter case, the true prevalence is underestimated (Figure 3A). No GPs has identified the true prevalence of hypertension, which is around $50-60 \%$ in patients with a diagnosis of OSAHS. OSAHS as an independent cardiovascular risk factor was correctly identified by $84 \%$ of respondents (Figure 3B). Currently the knowledge of the questionnaire "Sleepiness
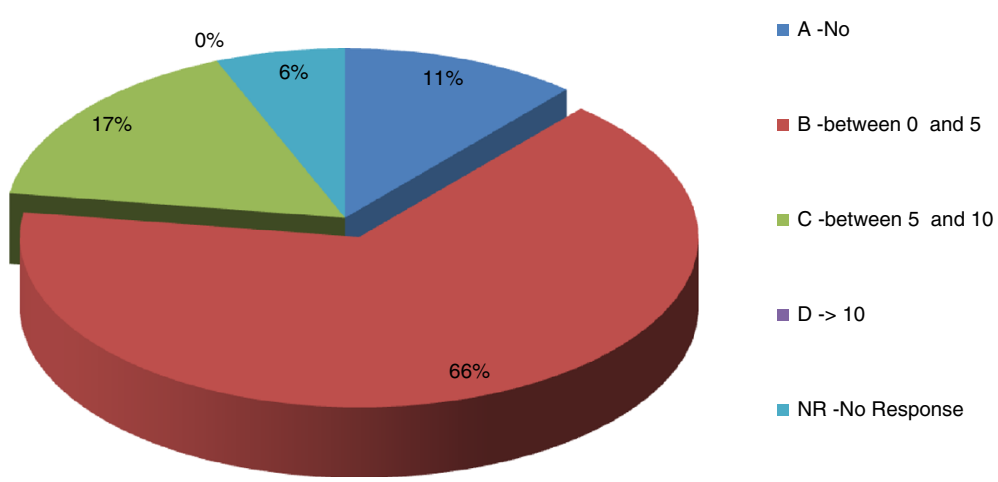

Figure 2 "Among your patients, how many have a diagnosis of OSAHS?" 


\section{A -Prevalence of OSAHS in the hypertensive patients.}

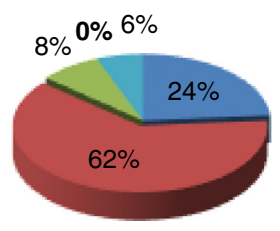

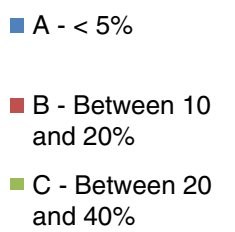

\section{B -OSAHS as indipendent cardiovascular} risk factor

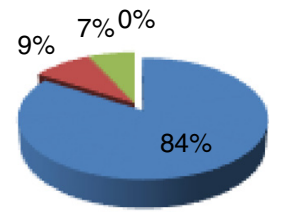

- A - Yes

B - No

- C - I dont' know

D - No Response

Figure 3 "Answers to the question about the prevalence of OSAHS in hypertensive patients $(3 \mathrm{~A})$ and about the perception of OSAHS as an independent cardiovascular risk factor (3B)".

Epworth Scale" is still poor. The latter assesses the likelihood of falling asleep or dozing off in various situations, which is a useful metric to suspecting OSAHS. $78 \%$ of the GPs surveyed did not know about it, while only $28 \%$ indicated to be aware but not to use it (Figure 4A). $60 \%$ of the GPs identifies the pulmonologist as the main contact person in the diagnosis of the OSAHS. $20 \%$ also identifies the need for a multidisciplinary team in the management of clinical and instrumental problem. The primary obstacles in accessing to specialist care were found to be the long waiting times (50\%), the difficulty of convincing the patient (22\%) and the complex interaction with the specialist (16\%) (Figure 4B), emphasizing a lack of hospital-community collaboration that is rather fundamental in the clinical management of chronic disorders such as OSAS. 70\% of respondents showed a good expertise in the diagnostic-therapeutic course of OSAHS, identifying in the polysomnography (Figure $5 \mathrm{~A}$ ) and in the C-PAP (Figure 5B) the diagnostic and therapeutic gold standards, respectively. $65 \%$ of GPs participating in the study is, however, aware of the lack of acceptance of the C-PAP by the patient, emphasizing the need for adequately trained personnel in education to the patient for the proper functioning of the C-PAP. In the $62 \%$ the respiratory therapist and the nurse are the healthcare providers who should compete primarily on the role of educator, while only $39 \%$ identified the GP and the pulmonologist for this role.

\section{Discussion and conclusions}

OSAHS is a common disorder in the general population but often underestimated and underdiagnosed. OSAHS is an independent risk factor for hypertension and cardiovascular disease and is the frequent underlying disease of secondary hypertension and resistant hypertension [9]. Randomized, controlled trials have evaluated the use of continuous positive airway pressure (CPAP) to reduce BP among persons with OSA. The benefits of OSA treatment are related to implications for hypertension management. Several lines of evidence have also identified OSAHS as an independent risk factor of secondary hypertension, such as obesity. According to most studies, the treatment of obstructive breathing disorders during sleep makes a significant clinical improvement by reducing both blood pressure nocturnal diurnal [10]. The pathophy-siological mechanisms underlying this phenomenon are not yet clear. However, several mechanisms have been proposed, including increased sympathetic activity in response to hypoxemia and hypercapnia resul-ting in the chemoreceptor activation and increased peripheral vascular tone. Other processes implycated include vasoconstrictors in the circulation, humoral factors such as Endothelin-1 (ET-1) and endothelial dysfunction $[11,12]$. Furthermore, patients with OSAHS could be more easily predisposed to a weight gain. The simultaneous presence of obesity and OSAHS increases the risk of hypertension. In this study, the point of view of GPs showed a good knowledge of the OSAHS regarding the epidemiology, the associated risk factors, the diagnostic

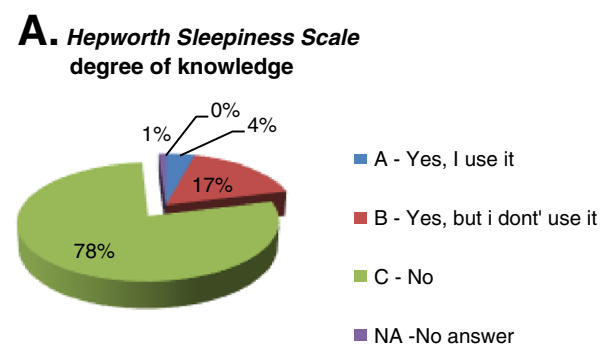

B. Problems for access to specialist care

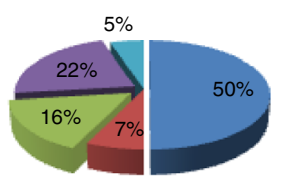

$$
\begin{aligned}
& \text { A - Waiting time } \\
& \text { B - Cost } \\
& \text { C - Communication with } \\
& \text { the specialist } \\
& \text { D - Degree of belief of the } \\
& \text { patient } \\
& \text { NA - No Anwer }
\end{aligned}
$$

Figure 4 GP's knowledge about the Hepworth questionnaire (A) and issues in access to specialist care (B). 


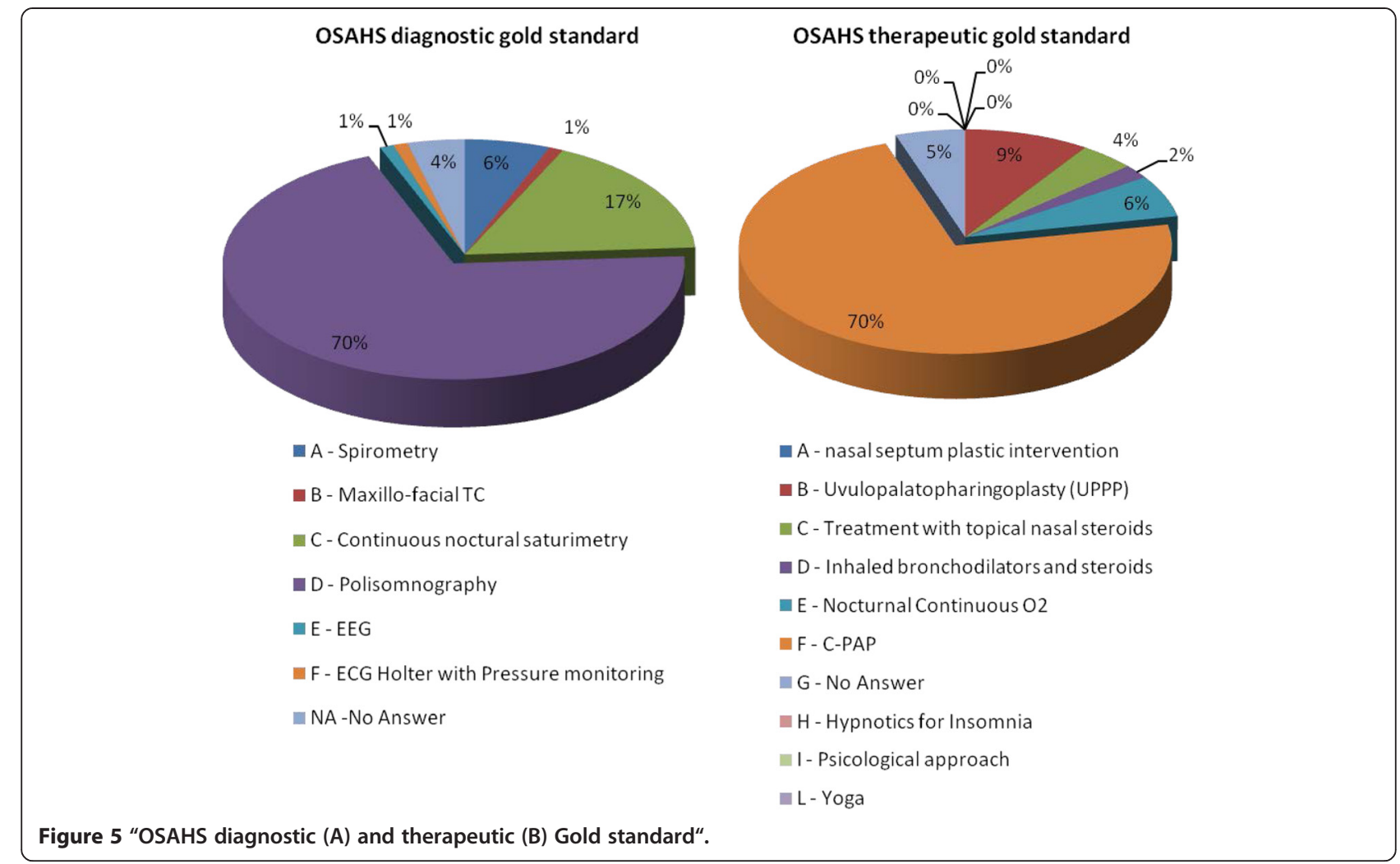

flow-chart, and therapeutic approach. The OSAHS is recognized by most of the GPs interviewed as disease in constant increase, associated with predisposing factors such as obesity, male sex, older age, use of hypnotics drugs and bad life habits such as alcohol abuse and cigarette smoking. High blood pressure is perceived as an independent cardiovascular risk factor in patients with OSAS, in line with major international studies and highlighting the importance of an appropriate treatment that can reduce blood pressure in both daytime and nighttime in these patients. Instead, the degree of knowledge of rating scales in the outpatients, such as Epworth Sleepiness Scale, resulted insufficient. The C-PAP has been identified as the gold standard of care in patients with OSAS, despite the lack of patient compliance in relation to this procedure, while polysomnography was found to be the main test instrument used in the diagnostic workup of OSAS. The pulmonologist and a multidisciplinary team have been identified as the specialist figures of reference to which to direct the patient through the diagnostic workup of OSAS despite the waiting time, the patient's belief tiring and difficult interaction with the specialist frequently represent the major barriers in accessing to specialist care. Finally, respiratory therapists and nurses represent the role of educator in the proper management of the C-PAP in the opinion of $62 \%$ of respondents, while only $34 \%$ think that this role should be played by the GP and the specialist reference. Overall, it appears essential, as well as in all chronic diseases in the growing number of patients with adult-age, a proper understanding of the problem and an integrated hospital-community to guide the patient with OSAS through the proper procedures and best diagnostic and therapeutic able to prevent, or limit, the complications of this disease $[13,14]$. The results of this study would allow to take appropriate educational actions and this questionnaire could be used to monitor the possible effects of divulgation and educational initiatives over time.

\section{Competing interests}

The authors declare that they have no competing interests.

\section{Authors' contributions}

All authors read and approved the final manuscript.

\section{Acknowledgements}

The authors thank all the general Practitionners who have contributed to the study by filling out the questionnaire.

\section{Author details}

${ }^{1}$ Allergy and Pneumology Departmental Unit, Fondazione Poliambulanza Hospital, Brescia, Italy. ${ }^{2}$ General Practitioner, SIMG (Società Italiana di Medicina Generale), Brescia, Italy. ${ }^{3}$ Division of Pulmunology, S. Corona Hospital, Pietra Ligure, Italy. ${ }^{4}$ Allergy Service, Verona Major Hospital, Verona, Italy. ${ }^{5}$ Allergy and Respiratory Diseases, DIMI, University of Genoa, Genoa, Italy.

Received: 13 January 2015 Accepted: 26 February 2015

Published online: 15 April 2015

\section{References}

1. Jennum P, Riha RL. "Epidemiology of sleep apnoea/hypopnoea syndrome and sleep-disordered breathing". Eur Respir J. 2009;33(4):907-14. 
2. Riha RL, Gislasson T, Diefenbach K. "The phenotype and genotype of adult obstructive sleep apnoea/hypopnoea syndrome". Eur Respir J. 2009:33(3):646-55.

3. Thurnheer R, Bloch KE, Laube I, Gugger M, Heitz M, Swiss Respiratory Polygraphy Registry. "Respiratory polygraphy in sleep apnoea diagnosis. Report of the Swiss respiratory polygraphy registry and systema-tic review of the literature". Swiss Med Wkly. 2007;137(5-6):97-102.

4. Robinson GV, Stradling JR, Davies RJ. "Obstructive sleep apnoea/hypopnoea syndrome and hypertension". Thorax. 2004;59(12):1089-94.

5. Destors M, Tamisier R, Baguet JP, Levy P, Pepin JL. "Cardiovascular morbidity associated with obstructive sleep apnea syndrome". Rev Mal Respir. 2014:31(4):375-85.

6. Bonsignore MR, Esquinas C, Barceló A, Sanchez-de-la-Torre M, Paternó A, Duran-Cantolla J, et al. "Metabolic syndrome, insulin resistance and sleepiness in real-life obstructive sleep apnoea". Eur Respir J. 2012;39(5):1136-43.

7. McDaid C, Durée KH, Griffin SC, Weatherly HL, Stradling JR, Davies RJ, et al. "A systematic review of continuous positive airway pressure for obstructive sleep apnoea hypopnoea syn-drome". Sleep Med Rev. 2009;13(6):427-36.

8. Krucien N, Le Vaillant M, Pelletier-Fleury N. "Adaptation and validation of the patient assessment of chronic illness care in the French context". BMC Health Serv Res. 2014;14:269.

9. Osada N. "Sleep apnea syndrome". Nihon Rinsho. 2014;72(8):1440-7.

10. Cross MD, Mills NL, Al-Abri M, Riha R, Vennelle M, Mackay TW, et al. "Continuous positive airway pressure improves vascular function in obstructive sleep apnoea/hypopnoea syndrome: a randomised controlled trial". Thorax. 2008:63(7):578-83.

11. Lavie L, Lavie P. "Molecular mechanisms of cardiovascular disease in OSAHS: the oxidative stress link". Eur Respir J. 2009;33(6):1467-84.

12. Karkoulias K, Lykouras D, Sampsonas F, Drakatos P, Canova S, Tsoukalas G, et al. "The role of Endothelin-1 in obstructive sleep apnea syndrome and pulmonary arterial hypertension: pathogenesis and Endothelin-1 antagonists". Curr Med Chem. 2010;17(11):1059-66.

13. Epstein $L$, Kristo D, Strollo PJ, Friedman N, Malhotra A, Patil SP, et al. "Clinical guideline for the evaluation, management and long-term care of obstructive sleep apnea in adults". J Clin Sleep Med. 2009;5(3):263-76.

14. Qaseem A, Dallas P, Owens DK, Starkey M, Holty JE, Shekelle P, et al. "Diagnosis of obstructive sleep apnea in adults: a clinical practice guideline from the American College of Physicians". Ann Intern Med. 2014;161:210-20.

\section{Submit your next manuscript to BioMed Central and take full advantage of:}

- Convenient online submission

- Thorough peer review

- No space constraints or color figure charges

- Immediate publication on acceptance

- Inclusion in PubMed, CAS, Scopus and Google Scholar

- Research which is freely available for redistribution 